\title{
STRATEGI PEMASARAN PADA PT. PRIMA MEGAH IRSA
}

\author{
Wahyu Ilham Pradana ${ }^{(1)}$ \\ Progran Studi Manajemen S1 \\ Fakultas Ekonomi \& Bisnis Universitas Muhammadiyah Gresik ${ }^{(1)}$ \\ e-mail: ${ }^{1}$ wahyuilhampradana20@gmail.com \\ Sukaris $^{(2)}$ \\ Progran Studi Manajemen S1 \\ Fakultas Ekonomi \& Bisnis Universitas Muhammadiyah Gresik ${ }^{(2)}$ \\ e-mail: ${ }^{2}$ sukaris21@umg.ac.id
}

\begin{abstract}
ABSTRAK
Tujuan dalam penelitian ini yaitu untuk mengetahui strategi apakah yang diterapkan oleh PT. Prima Megah Irsa dalam meningkatkan penjualan jasa kontruksi. Penelitian ini dilakukan di PT. Prima Megah Irsa yang beralamatkan di Jalan Krikilan No 146 Ds. Krikilan RT. 013 RW. 005 Kec. Driyorejo Kab. Gresik. Jenis penelitian ini yaitu kualitatif deskriptif. Sumber data yang digunakan dalam penelitian ini yaitu sumber data primer. Sedangkan pengumpulan data yang dilakukan dalam penelitian ini menggunakan metode observasi, wawancara, dan dokumentasi. Adapun hasil penelitian ini dapat disimpulkan bahwa 1) PT. Prima Megah Irsa memiliki strategi pemasaran yang sangat penting dalam meningkatkan volume penjualan produk jasa yang disediakan, 2) Strategi produk yang dijalankan oleh PT. Prima Megah Irsa mengfokuskan pada kualitas produk jasa dan proses pengerjaan proyek yang selesai sesuai dengan waktu yang ditetapkan, 3) Strategi harga yang ditawarkan oleh PT. Prima Megah Irsa merupakan harga yang ditawarkan sesuai dengan harga di pasar, 4) Strategi distribusi yang dilakukan oleh PT. Prima Megah Irsa merupakan sistem strategi distribusi langsung. Strategi langsung merupakan strategi yang bertujuan untuk melakukan pendekatan secara langsung kepada para calon pengguna jasa (klaen) baik secara formal maupun informal guna produk jasa yang ditawarkan perusahaan dapat berkembang dan dikenal lebih luas oleh perusahaan, 5) Strategi promosi dan komunikasi yang dilakukan oleh PT. Prima Megah Irsa yaitu dengan cara melakukan promosi secara langsung kepada para pengusaha kontraktor. Perusahaan juga menjalin komunikasi dengan para pengusaha kontraktor lainnya. Yang tujuannya produk jasa yang ditawarkan lebih dikenal oleh pasar dengan cara word of mouth.
\end{abstract}

Kata Kunci: Strategi Pemilihan Pasar, Strategi Produk, Strategi Harga, Strategi Distribusi, Strategi Promosi dan Komunikasi

\section{ABSTRACT}

The purpose of this research is to find out what strategy is applied by PT. Prima Megah Irsa in increasing sales of construction services. This research was conducted at PT. Prima Megah Irsa whose address is at Jalan Krikilan No. 146 Ds. Krikilan RT. 013 RW. 005 District. Driyorejo Kab. Gresik. This type of research is descriptive qualitative. The data sources used in this study are primary data sources. While the data collection was carried out in this study using the methods of observation, interviews, and documentation. The results of this study can be concluded that 1) PT. Prima Megah Irsa has a very important marketing strategy in increasing the sales volume of the services provided, 2) the product strategy implemented by PT. Prima Megah Irsa focuses on the quality of service products and project work processes that are completed in accordance with the specified time, 3) the price strategy offered by PT. Prima Megah Irsa is the price offered in accordance with the price in the market, 4) distribution strategy carried out by PT. Prima Megah Irsa is a direct distribution strategy system. The direct strategy is a strategy that aims to make a direct approach to prospective service users (clients) both formally and informally so that the products and services offered by the company can develop and be known more widely by the company, 5) promotion and communication strategies 
carried out by PT. Prima Megah Irsa, namely by making promotions In addition, the company also establishes communication with other contractor entrepreneurs. The goal is that the products and services offered are better known by the market by word of mouth.

Keywords: Market Selection Strategy, Product Strategy, Pricing Strategy, Distribution Strategy, Promotion and Communication Strategy

\section{PENDAHULUAN}

Ditengah kondisi persaingan usaha yang sangat komplek ini, banyak pelaku usaha bersaing secara sehat untuk mengeksistensikan usaha yang mereka jalankan. Salah satu usaha yang saat ini banyak diminati oleh para pengusaha yaitu usaha jasa kontraktor. Para pengusaha saling menunjukan kelebihan masing-masing agar usaha jasa yang mereka jalankan tetap berjalan sesuai dengan apa yang diharapkan oleh perusahaan. Adapun permasalahan dalam penelitian ini yaitu strategi pemasaran apakah yang diterapkan oleh PT. Prima Megah Irsa dalam meningkatkan penjualan jasa kontruksi? Dan tujuan dalam penelitian ini yaitu untuk mengetahui strategi apakah yang diterapkan oleh PT. Prima Megah Irsa dalam meningkatkan penjualan jasa kontruksi. Namun dengan kondisi yang seperti ini, manajemen pemasaran perusahaan mengendalikan peranan yang sangat penting dalam menganalisis peluang-peluang pasar yang ada. Menajemen pemasaran memiliki hubungan paling besar dengan lingkungan eksternal perusahaan, tidak hanya berfungsi sebagai penganalisis peluang pasar, namun secara keseluruhan manajemen pemasaran perusahaan berfungsi untuk memenangkan ketatnya persaingan pasar. Dengan adanya persaingan pasar maka perusahaan dituntut untuk mempunyai strategi pemasaran.

Strategi menurut Charles (2010:9) merupakan keseluruhan konsep perusahaan yang dapat mengatur dirinya sendiri dan semua kegiatan yang memiliki tujuan supaya bisnis yang dijalankan dapat berhasil, melakukan persaingan, dan melakukan imbal hasil kepada pemegang saham. Rahmawati (2016:3) berpendapat bahwa pemasaran merupakan sebuah tindakan aktivitas yang memiliki tujuan untuk mengidentifikasi dan menemukan kebutuhan manusia. Secara rinci pemasaran dapat didefinisikan sebagai "meeting needs profitably" yaitu bagaimana perusahaan dapat memenuhi kebutuhan konsumen dengan cara yang menguntungkan bagi konsumen dan perusahaan. Adapun fungsi pemasaran yaitu menjembatani hubungan antara perusahaan dengan para konsumen. Peranan lainnya yaitu memfasilitasi proses identifikasi peluang produk, pendefinisian segmen pasar, dan identifikasi kebutuhan pelanggan. Bagian pemasaran juga secara khusus merancang komunikasi antara perusahaan dengan pelanggan, menetapkan target harga dan merancang peluncuran serta promosi produk (Hanafiah et al, 2020). Sedangkan strategi pemasaran menurut Assauri (2013:15) yaitu serangkaian tujuan dan sasaran, kebijakan dan aturan yang dapat memberikan arah kepada usahausaha pemasaran perusahaan dari waktu kewaktu, pada masing-masing tingkatan, acuan serta alokasinya, terutama sebagai tanggapan perusahaan dalam menghadapi lingkungan dan keadaan persaingan yang berubah-ubah. Jasa merupakan setiap aktivitas, manfaat atau performance yang ditawarkan oleh satu pihak ke pihak lain yang memiliki sifat intangible dan tidak menyebabkan perpindahan kepemilikan apapun dimana dalam produksinya dapat terikat maupun tidak dengan produk fisik (Kotler \& Keller, 2012:67). Terdapat tiga tipe pemasaran perusahaan jasa dalam dunia usaha , antara lain yaitu:

1) Pemasaran eksternal (External Marketing), strategi pemasaran eksternal ini dikenal dengan 4P (Product, Price, Promotion, Place).

2) Pemasaran internal (Internal Marketing), pemasaran jasa tidak cukup hanya dengan pemasaran eksternal (4P) tetapi harus diikuti dengan peningkatan kualitas atau keterampilan para personil yang ada dalam perusahaan. 
3) Pemasaran Interaktif (Interaktif Marketing), kepuasan konsumen tidak hanya terletak pada mutu saja (Fatihudin \& Firmansyah, 2019:15).

Menurut Atmoko (2018), keberhasilan suatu perusahaan dalam mencapai suatu tujuan yang telah ditetapkan perusahaan tergantung dari strategi perusahaan tersebut. Salah satu alat yang dapat digunakan dalam menyusun strategi pemasaran adalah dengan menggunakan bauran pemasaran. Menurut Kotler dalam Entaresmen \& Pertiwi (2016) bauran pemasaran (Marketing Mix) yaitu seperangkat alat pemasaran yang dapat digunakan perusahaan untuk suatu tujuan pemasarannya di pasar sasaran.

Menurut Corey dalam Darmawan (2012), strategi pemasaran jasa terdiri atas lima elemen yang dapat saling terkait, lima elemen strategi pemasaran tersebut yaitu:

1) Pemilihan Pasar

Yaitu memilih pasar yang dilayani oleh perusahaan sesuai dengan faktor-faktor sebagai berikut:

a. Persepsi terhadap fungsi produk dan pengelompokan teknologi yang dapat diproteksi dan didominasi.

b. Keterbatasan sumber daya internal yang mendorong perlunya pemusatan (focus) yang lebih sempit.

c. Pengalaman kumulatif yang didasarkan pada trial-and-error di dalam menanggapi peluang dan tantangan.

d. Kemampuan khusus yang berasal dari akses terhadap sumber daya langka atau pasar yang terproteksi.

2) Perencanaan Produk

Perencanaan produk dapat meliputi produk spesifik yang dijual, pembentukan lini produk, dan desaig penawaran individual pada masing-masing lini.

3) Penetapan Harga

Penetapan harga merupakan penentuan nilai harga yang dapat mencerminkan nilai kuantitatif dari produk kepada pelanggan.

4) Sistem Distribusi

Sistem distribusi merupakan saluran perdagangan grosir dan eceran yang dilewati produk hingga mencapai konsumen akhir yang membeli dan menggunakannya.

5) Komunikasi Pemasaran (Promosi)

Komunikasi pemasaran (promosi) meliputi periklanan, personal selling, promosi penjualan, direct marketing, public relations.

Dalam perusahaan kontraktor memiliki karakteristik strategi pemasaran yaitu pemilihan pasar, produk, harga, distribusi, dan promosi. Karakteristik tersebut akan memberikan gambaran umum tentang strategi pemasaran produk jasa kontraktor. Perbedaan dalam hal penyusunan rencana pemasaran pada kontraktor yang berskala besar, menengah, dan kecil. Hal tersebut tampaknya tidak mempengaruhi strategi pemasaran mereka secara umum berbeda satu sama lainnya. Hal tersebut ditunjukan dengan tidak adanya perbedaan yang berarti antara kontraktor berskala besar, menengah dan kecil dalam melaksanakan strategi pemilihan pasar sasaran (market selection) dan strategi bauran pemasaran (marketing mix).

\section{METODE PENELITIAN}

\section{Jenis Penelitian}

Jenis penelitian ini yaitu menggunakan metode diskriptif dengan menggunkan pendekatan kualitatif. Tujuan dalam penelitian ini yaitu agar peneliti dapat menggambarkan keadaan yang sesungguhnya sesuai dengan kenyataan, menggali dan menganalisis lebih mendalam terkait strategi pemasaran PT. Prima Megah Irsa dalam 
penjualan jasa kontraktor.

\section{Fokus Penelitian}

Fokus dalam penelitian ini yaitu strategi pemasaran pada PT. Prima Megah Irsa dalam peningkatan penjualan jasa kontraktor.

\section{Sumber Data}

Sumber data yang digunakan dalam penelitian ini yaitu sumber data primer yang berupa hasil wawancara dengan pihak PT. Prima Megah Irsa.

\section{Teknik Pengumpulan Data}

Peneliti dalam penelitian menggunakan wawancara dan dokumentasi yang diperoleh dari pihak PT. Prima Megah Irsa.

\section{HASIL DAN PEMBAHASAN}

\section{Sejarah Perusahaan}

PT. Prima Megah Irsa adalah kontraktor berpengalaman yang mengerjakan proyek nasional yang beralamat di Jalan Krikilan No 146 Ds. Krikilan RT. 013 RW. 005 Kec. Driyorejo Kab. Gresik. PT. Prima Megah Irsa memperoleh pekerjaannya di Dinas PUTR (Pekerjaan Umum dan Tata Ruang), PLTR di beberapa Kab. Gresik, dan BUMN (PT. PJB (Pembangkit Jawa Bali), PELINDO, \& PETRO Group). PT. Prima Megah Irsa berdiri pada tanggal 13 Maret 2010 dengan direktur utama Ir. Khoirul Aman Makhrudy, M.M. Pak Rudy merupakan lulusan Teknik Industri Universitas Muhammadiyah Gresik tahun 1995 dan menyelesaikan S2 Manajemen di Universitas Indonesia. Untuk mendapatkan pekerjaannya itu semua, PT. Prima Megah Irsa sudah mempunyai persyaratan-persyaratan tersebut antara lain :

1. Akte Pendirian

2. Menkumham

3. NIB (Nomor Induk Berusaha)

4. NPWP

5. PKP (Perusahaan Kena Pajak)

6. Domisili Perusahaan

7. BPJS Tenaga Kerja

8. Sertifikasi Badan Usaha Jasa Konstruksi (SBUJK)

9. Brosur

10. SMK III (Sistem Manajemen Keselamatan dan Kesehatan Kerja)

11. SKA (Sertifikasi Keahlian)

Dengan persyaratan-persyarataan tersebut, PT. Prima Megah Irsa sudah bisa melakukan lelang baik dari pemerintahan maupun BUMN. Bahkan PT. Prima Megah Irsa juga terkadang melayani konsumen dari pihak swasta yang sesuai dengan kesepakatan harga yang ditawarkan. PT. Prima Megah Irsa juga memiliki beberpa karyawan yang bergerak dalam bidangnya masing-masing yang telah dibentuk yang telah memenuhi kriteria yang ditetapkan oleh perusahaan.

\section{Strategi Pemasaran Yang Diterapkan oleh PT. Prima Megah Irsa Meningkatkan Penjualan Produk Jasa}

Belajar dari pengalaman yang telah dilalui oleh PT. Prima Megah Irsa banyak hal yang berpengaruh terhadap kesuksesan dalam memasuki dunia bisnis kontraktor. Pengalaman tersebut sangat berarti bagi perusahaan untuk melakukan perkembangan 
yang lebih besar lagi. Bahwa pemilik PT. Prima Megah Irsa berencana untuk memiliki usaha lainnya yang tidak berhubungan dengan dunia kontraktor. Dengan banyaknya proyek yang telah dikerjakan oleh PT. Prima Megah Irsa sehingga perusahaan tersebut dapat bersaing dengan tender-tender yang ada di Indonesia. Keberhasilan perusahaan kontraktor ini dikarenakan strategi pemasaran yang dijalankan sangat bagus. Berikut strategi pemasaran yang dilakukan oleh PT. Prima Megah Irsa yaitu sebagai berikut:

1. Strategi Pemilihan Pasar

Dalam pemilihan pasar jasa kontraktor yang dilakukan oleh PT. Prima Megah Irsa memiliki tujuan untuk mengisi adanya peluang atau prospek yang sangat bagus terhadap usaha jasa yang ditawarkan. Dalam dunia bisnis adanya persaingan dan perbedaan treatment yang diberikan dapat menyebabkan pengusaha kontraktor mengelompokan pasarnya agar memahami struktur pasar yang akan dilayaninya. Dalam pengelompokan pasar difokuskan pada selera klien akan produk-produk jasa yang perlu disediakan dan untuk siapa pengguna dari produk yang akan disiapkan. Hasil penelitian menunjukan bahwa kontraktor kontruksi saat ini memiliki kecenderungan yang lebih tinggi untuk melayani klien pemerintahan dibandingkan dengan klien swasta atau perseorangan. Perusahaan kontraktor yang lebih besar terkesan lebih mampu melayani segmen pasar dibangdingkan dengan perusahaan kontraktor yang lebih kecil yang pada dasarnya perusahaan kontraktor PT. Prima Megah Irsa yang merupakan perusahaan kontraktor berskala nasional.

2. Strategi Produk

Strategi produk merupakan salah satu variabel penelitian yang dapat mempengaruhi tanggapan konsumen yang memiliki ruang geraknya masih dalam jangkauan pimpinan perusahaan yaitu produk jasa. Strategi atau kebijakan penting yang diambil perusahaan dalam hubungannya dengan produk yaitu dipusatkan dalam kualitas jasa serta proses pengerjaannya. Jumlah produk jasa yang sudah beredar dari masingmasing perusahaan mengakibatkan keadaan pasar menjadi persaingan mutu produk jasa. Dengan begitu perusahaan PT.Prima Megah Irsa mempertahankan kualitas produk jasa yang ditawarkannya. Hal tersebut sangat diperhatikan agar reputasi dari perusahaan tetap terjaga. Sehingga perusahaan mengurangi resiko akan komplain dari klaen atas kualitas produk jasa yang ditawarkan. Perusahaan akan selalu memberikan produk jasa yang terbaik mulai dari proses pengerjaan sampai dengan finishing sesuia dengan waktu yang telah disepakati. Sehingga, dengan begitu strategi yang ditawarkan perusahaan sangatlah berpengaruh terhadap kualitas produk jasa yang ditawarkan kepada klaen baik kepihak pemerintah maupun swasta. Perusahaan PT. Prima Megah Irsa terus berusaha memberikan kualitas produk jasa yang paling baik agar para konsumen tetap puas akan produk jasa tersebut.

3. Strategi Harga

Dalam strategi harga penetapan harga yang ditawarkan sangat mempengaruhi akan kelangsungan berjalannya suatu perusahaan. Harga merupakan elemen yang sangat penting karena harga merupakan satu-satunya elemen yang mempengaruhi pendapatan dari perusahaan. Perusahaan akan memilih pengguna jasa kontruksi yang memberikan harga penawaran tertinggi terhadap produk jasanya yang telah diajukan, sehingga kemudiam akan dituangkan dalam rencana anggaran biaya (RAB) sampai kedalam kontrak perjanjian kerja yang dimana telah ada persetujuan harga antara perusahaan dan pengguna jasa, baik dari pihak swasta maupun penggun jasa dari pihak pemerintah. Harga yang ditawarkan biasanya berdasarkan pasar dan bahan baku. Perusahaan akan mengevaluasi dan menganalis harga rencana anggaran biaya dari pengguna jasa yang ditawarkan dengn harga dipasar. Apabila harga yang ditawarkan sesuai dengan harga kondisi pasar dan sesuai dengan anggaran 
perusahaan maka pihak perusahaan akan melakukan penandatanganan kontrak harga paket kerjaan yang akan dilaksanakan atau dikerjakan.

4. Strategi Distribusi

Strategi pemasaran pada variabel distribusi yang dilakukan oleh perusahaan yaitu dengan cara distribusi langsung. Dari strategi pemasaran secara distribusi langsung lebih cendurung untuk menjangkau pasar sasaran dengan cara kontak langsung dengan calon pengguna jasa kontruksi. Sehingga berdampak kepada rendahnya jumlah perantara atau pihak ketiga dalam menjalankan proyek yang akan dijalankan. Hal tersebut dikarenakan bahwa pihak perusahaan menginginkan terjadinya kontak langsung antara kontraktor dengan pengguna jasa (costumer), dengan demikian perusahaan berharap ada suatu hubungan (relationship) yang berkelanjutan. Selain dengan kontak langsung perusahan juga memiliki pendekatan-pendekan yang khusus yaitu secara formal maupun informal yang memiliki tujuan agar para calon pengguna jasa (costumer) untuk melakukan pembelian produk jasa yang perusahan tawarkan.

5. Strategi Promosi dan Komunikaai

Promosi merupakan salah satu cara perusahan menawarkan jasanya agar dilihat oleh calon para konsumen. Dengan melakukan berbagai macam strategi pemasaran promosi merupakan langkah awal yang dilakukan oleh perusahaan. Dengan cara melakukan promosi perusahaan berharap agar minat konsumen atas jasa yang ditawarkan oleh perusahaan semakin naik. PT. Prima Megah Irsa juga melakukan promosi dengan cara promosi langsung kedalam perusahan-perusahaan kontraktor ternama di Indonesia. Dengan mengikuti berbagai macam cara promosi, perusahaan bermaksud agar terlihat bahwa perusahaan akan menjangkau pasar sasaran yang lebih luas. Perusahaan juga mengelurkan anggaran khusus untuk melakukan promosi kepada masyarakat luas maupun ke dalam lingkungan pemerintahan (BUMN). PT. Prima Megah Irsa juga menjalin komunikasi dengan sesama pengusaha kontraktor guna mendapatkan informasi mengenai tander yang akan mereka menangkan. PT. Prima Megah Irsa juga merupakan anggota dari GAPENSI (Gabungan Pelaksana Kontruksi Nasional Indonesia). Dari para pengusaha tersebut sedikit banyaknya nama perusahaan yang dibangun dikenal oleh pengusaha lain. Promosi tersebut merupakan promosi yang dilakukan dari mulut ke mulut (word of mouth). Dengan begitu perusahaan akan lebih terkenal baik kepada calon pengguna jasa maupun kepada para pengusaha kontraktor lainnya. Oleh sebab itu PT. Prima Megah Irsa sangat menjaga hubungan dan komunikasi dengan baik kepada seluruh masyarakat.

\section{PENUTUP}

\section{Kesimpulan}

Berdasarkan hasil pemaparan pembahasan diatas maka dapat dimpulkan bahwa :

1) PT. Prima Megah Irsa memiliki strategi pemasaran yang sangat penting dalam meningkatkan volume penjualan produk jasa yang disediakan.

2) Strategi produk yang dijalankan oleh PT. Prima Megah Irsa mengfokuskan pada kualitas produk jasa dan proses pengerjaan proyek yang selesai sesuai dengan waktu yang ditetapkan.

3) Strategi harga yang ditawarkan oleh PT. Prima Megah Irsa merupakan harga yang ditawarkan sesuai dengan harga di pasar.

4) Strategi distribusi yang dilakukan oleh PT. Prima Megah Irsa merupakan sistem strategi distribusi langsung. Strategi langsung merupakan strategi yang bertujuan untuk melakukan pendekatan secara langsung kepada paracalon pengguna jasa (klaen) baik secara formal maupun informal guna produkjasa yang ditawarkan perusahaan dapat berkembang dan dikenal lebih luas oleh perusahaan. 
5) Strategi promosi dan komunikasi yang dilakukan oleh PT. Prima Megah Irsa yaitu dengan cara promosi secara langsung kepada kelompok pengusaha kontraktor di Indonesia. Selain itu perusahaan juga menjalin komunikasi dengan para pengusaha kontraktor lainnya. Yang tujuannya produk jasa yang ditawarkan lebih dikenal oleh pasar dengan cara word of mouth.

\section{Saran}

Berdasarkan hasil penelitian ini, maka saran yang dapat diberikan kepada PT. Prima Megah Irsa yaitu:

1) Perusahaan dalam memilih karyawan dalam bidang pemasaran hendaknya tenaga ahli di bidang manajemen pemasaran, dan juga diikut sertakan dalam pelatihan pemasaran.

2) Perusahaan harus lebih meningkatkan mutu dan kualitas produk jasa kontruksi.

3) Selalu menjaga hubungan baik dengan para konsumen dan para pengusaha kontraktor lainnya.

\section{DAFTAR PUSTAKA}

Assauri, Sofjan. (2013). Manajemen Pemasaran. Jakarta: Rajawali Pers.

Atmoko, T. P. H. (2018). Strategi Pemasaran Untuk Meningkatkan Volume Penjualan di Cavinton Hotel Yogyakarta. Journal of Indonesian Tourism, Hospitality and Recreation, 8.

Charles E, Bamfor. (2010). Strategy: Sustainable Advance and Performance. Canada: South Western Cengage Learning.

Entaresmen, R. A., \& Pertiwi, D. P. (2016). Strategi Pemasaran Terhadap Penjualan Produk Tabungan IB Hasanah di PT. Bank Negara Indonesia Syariah Kantor Cabang X. Jurnal Manajemen dan Pemasaran Jasa, 9.

Fatihudin, D., \& Firmansyah, M. A. (2019). Pemasaran Jasa (Strategi, Mengukur Kepuasan, dan Loyalitas Pelanggan). Yogyakarta: CV. Budi Utama.

Hanafiah, H., Mulyani, A., \& Kurniawanto, H. (2020). Strategi Pemasaran New Development Product (NDP) Pada Perusahaan Jasa Pest Control dalam Menghadapi Wabah Covid-19. Jurnal Ekonomika, 13(10.46306/jbbe.v13i2 ), 02.

Kotler Philip dan Kevin Lane Keller, (2012) Manajemen Pemasaran.Edisi bahasa Indonesia. Edisi 13 Jilid 2. Jakarta. Erlangga

Rahmawati. (2016). Manajemen Pemasaran. Samarinda: University Mulawarman Press. 
